\title{
Aerobic Oxidation of Alcohols over Ru-Mn-Ce and Ru-Co-Ce Catalysts: The Effect of Calcination Temperature
}

Gui Liu, Junhua Liu, Wenxiu Li, Cheng Liu, Fang Wang, Junkai He, Curtis Guild, Jing Jin, Dave Kriz, Steven L. Suib

Series of $\mathrm{Ru}-\mathrm{Mn}-\mathrm{Ce}$ and $\mathrm{Ru}-\mathrm{Co}-\mathrm{Ce}$ catalysts are prepared and used in the aerobic oxidation of alcohols, the calcination temperature had an adverse effect on the catalytic performance of $\mathrm{Ru}-\mathrm{Mn}-\mathrm{Ce}$ catalysts, while it was beneficial to the $\mathrm{Ru}-\mathrm{Co}-\mathrm{Ce}$ catalysts, which is an interesting finding, and this is an environmental friendly and economical catalytic systems. The interactions between ruthenium oxides and Co (Mn)-Ce mixed oxides of the former strengthened while the latter weakened after calcination. Calcination decreased the content of adsorbed oxygen and restricted oxygen transfer mechanism in the manganese system, while the opposite effect was observed with the cobalt-containing catalyst.
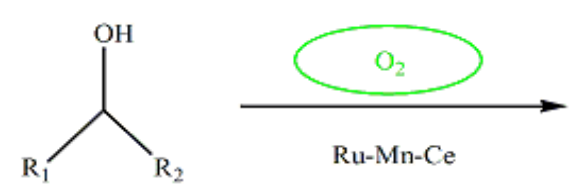<smiles>[R]C([R])=O</smiles> 


\title{
Aerobic Oxidation of Alcohols over Ru-Mn-Ce and Ru-Co-Ce \\ Catalysts: The Effect of Calcination Temperature
}

Gui Liu ${ }^{a}$, Junhua Liu ${ }^{a b^{*}}$, Wenxiu $\mathrm{Li}^{a}$, Cheng Liu ${ }^{a}$, Fang $\mathrm{Wang}^{{ }^{*}}$, Junkai He${ }^{d}$, Curtis Guild ${ }^{d}$, Jing $\mathrm{Jin}^{d}$, David Kriz ${ }^{d}$, Steven L. Suib ${ }^{d^{*}}$

${ }^{a}$ College of Chemistry and Materials Science, Nanjing Normal University, Nanjing 210023, China

${ }^{b}$ Jiangsu Collaborative Innovation Center of Biomedical Functional Materials, Jiangsu Key Laboratory of Biomedical Materials, College of Chemistry and Materials Science, Nanjing Normal University, Nanjing 210023, China

${ }^{c}$ College of Chemistry and Molecular Engineering, Nanjing Tech University, Nanjing 210009, China

${ }^{d}$ Department of Chemistry, University of Connecticut, Storrs, Connecticut 06269, USA

\begin{abstract}
Two ternary mixed oxides, Ru-Mn-Ce and Ru-Co-Ce, were prepared by a co-precipitation method and used in the aerobic oxidation of alcohols to corresponding aldehydes (ketones). Interestingly, different catalytic results were obtained when these compounds were calcined. The calcination temperature had an adverse effect on the catalytic performance of Ru-Mn-Ce catalysts, while being beneficial to the Ru-Co-Ce catalysts. To illustrate these effects, these materials were characterized using X-ray diffraction (XRD), Fourier transformed infrared spectroscopy (FT-IR), X-ray photoelectron spectroscopy (XPS), Temperature-programmed reduction (TPR), Electron paramagnetic resonance (EPR) and other techniques. The data showed that ruthenium oxides were uniformly dispersed in the mixed oxides, and phase transformations occur after calcination. $\mathrm{Mn}_{3} \mathrm{O}_{4}$ was transformed to $\mathrm{MnO}_{2}$ for the $\mathrm{Ru}-\mathrm{Mn}$-Ce catalyst, while $\mathrm{CoO}(\mathrm{OH})$ was transformed to $\mathrm{Co}_{3} \mathrm{O}_{4}$ in the $\mathrm{Ru}-\mathrm{Co}-\mathrm{Ce}$ catalyst. The interactions between ruthenium oxides and Co (Mn)-Ce mixed oxides of the former strengthened while the latter weakened. Calcination decreased the content of adsorbed oxygen and restricted oxygen transfer mechanism in the manganese system, while the opposite effect was observed with the

\footnotetext{
${ }^{*}$ Corresponding author. Tel: +86-25-85891767

E-mail address: liujh2007@aliyun.com (Dr. Liu); steven.suib@uconn.edu (Dr. Suib)
} 
cobalt-containing catalyst. Under optimal reaction conditions, various kinds of alcohols were transformed to corresponding aldehydes (ketones) in high yields over the Ru-Mn-Ce catalyst suggesting these ternary oxides are environmental friendly and economical catalytic systems.

Keywords: Aerobic oxidation; Co-precipitation method; Mixed oxides; Oxidation of alcohols.

\section{Introduction}

Selective oxidation of alcohols to aldehydes (ketones) has been considered as one of the most fundamental organic reactions, with the products widely used in the manufacture of perfumes, agricultural chemicals, and other fine chemicals [1-3]. Environmental and economic concerns lead researchers to require clean oxidation procedures that minimize byproducts and wastes, affected by replacing the conventional stoichiometric methods with atom-efficient catalytic protocols using molecular oxygen as the sole oxidant. Recently many outstanding results have been reported using noble metals ( $\mathrm{Ru}, \mathrm{Pd}, \mathrm{Au}$, etc.) as heterogeneous catalysts [3-6]. However, these supported catalysts always face the loss of the noble metals, which is a critical issue for the reusability of catalysts.

Much attention has been given to mixed metal oxides (MMOs), usually prepared by a one-pot synthesis method, e.g. the metal doped vanadium phosphorus mixed oxides (M-VPOs) [7-8] and metal doped molecular sieves [9-10]. In these systems, noble metals are doped into the catalysts directly, forming a uniform compound which minimizes synthesis and loss of the metals. Additionally, noble metals also can be put into catalysts by a co-precipitation method, generally uniform mixed oxide (hydroxide) catalysts. These materials containing noble metals are formed when metal precursor solutions are carefully mixed under vigorous stirring, yielding solid precipitates [11-12]. For aerobic oxidative catalysts, most researchers believe that excellent catalytic performance originates from highly dispersed metal components and rich oxygen storage capacity, surface oxygen vacancies and defects, and some mixed oxides consisting of cerium oxide, zirconium oxide and iron oxide, have been used for oxidative reactions [13-14].

For MMOs, more active oxygen species can be produced due to the synergistic interaction of different oxides, and they show more excellent catalytic performance than unmixed ones [14-15]. To date, ternary mixed oxides containing noble metals are rarely reported. In this article, $\mathrm{Ru}-\mathrm{Mn}-\mathrm{Ce}$ and Ru-Co-Ce ternary-mixed-oxides were prepared by a co-precipitation method and 
were investigated as catalysts for aerobic oxidation of alcohols. Interestingly, the calcination temperature has an adverse effect on oxidation of benzyl alcohol over Ru-Mn-Ce catalysts, while being beneficial over the Ru-Co-Ce catalysts.

\section{Experimental}

\subsection{Catalyst preparation}

A certain amount of $\mathrm{Na}_{2} \mathrm{CO}_{3}(0.5 \mathrm{M})$ and $\mathrm{NaOH}(1.5 \mathrm{M})$ was slowly dissolved in $30 \mathrm{~mL}$ distilled water to produce solution A. Solution B was composed by dissolving $2.2140 \mathrm{~g}$ of Ce $\left(\mathrm{NO}_{3}\right)_{2} \cdot 6 \mathrm{H}_{2} \mathrm{O}, 2.5000 \mathrm{~g}$ of $\mathrm{Mn}\left(\mathrm{CH}_{3} \mathrm{COO}\right)_{2}\left(\mathrm{n}_{\mathrm{Ce}} / \mathrm{n}_{\mathrm{Mn}}=0.5\right)$ and $0.317 \mathrm{~g}$ of $\mathrm{RuCl}_{3}$ in $20 \mathrm{~mL}$ distilled water. Solution A was then slowly dripped into solution B under vigorous stirring. The resulting solid product was aged in the mother liquor at room temperature for $24 \mathrm{~h}$, and then the dark brown product was filtered, washed with distilled water, and dried at $110^{\circ} \mathrm{C}$ for $10 \mathrm{~h}$ to obtain a black powder. The catalysts were calcined at $300^{\circ} \mathrm{C}$ and $500^{\circ} \mathrm{C}$, yielding materials referred to hereafter as Ru-Mn-Ce, Ru-Mn-Ce (300) and Ru-Mn-Ce (500), respectively. Ru-Co-Ce catalysts were prepared by a similar procedure with $\mathrm{Co}\left(\mathrm{CH}_{3} \mathrm{COO}\right)_{2} \cdot 4 \mathrm{H}_{2} \mathrm{O}$, the black powders obtained were calcined at $300^{\circ} \mathrm{C}$ and $500^{\circ} \mathrm{C}$, which are signed as Ru-Co-Ce, Ru-Co-Ce (300) and Ru-Co-Ce (500), respectively.

\subsection{Catalyst characterization}

The morphologies of obtained catalysts were examined by transmission electron microscopy (TEM) (FEI Talos F200X) and scanning electron microscopy (SEM) (JSM-7600F). The crystals of the catalysts were studied by X-ray diffraction (XRD) (X'Pert PRO PANalytical). Specific surface area was measured by $\mathrm{N}_{2}$ adsorption-desorption experiments at $77 \mathrm{~K}$ in an ASAP 2010 instrument. The surface composition was determined by X-ray photoelectron spectroscopy (XPS) (VG ESCALAB210) using a K-Alpha-surface analysis system with monochromatized X-Rays. FT-Infrared spectroscopy was performed on a Bruker Tensor 27 spectrometer. Raman spectra were recorded in a dispersive Horiva Jobin Yvon LabRam HR800 Confocal Raman Microscope with a $20 \mathrm{~mW}$ green laser $(532.14 \mathrm{~nm})$ without a filter and using a 600 grooves $/ \mathrm{mm}$ grating. Temperature-programmed reduction (TPR) of catalysts was carried out on a Micromeritics 2920 apparatus. Catalyst samples $(60 \mathrm{mg})$ were heated to $800^{\circ} \mathrm{C}$ at a rate of $10^{\circ} \mathrm{C} / \mathrm{min}$ in a $\mathrm{H}_{2}-\mathrm{Ar}(5: 95)$ gas flow $\left(50 \mathrm{~cm}^{3} / \mathrm{min}\right)$. The electron paramagnetic resonance (EPR) spectra were recorded on a Bruker (EMXNano) spectrometer, all spectra were recorded at a power of $0.3 \mathrm{~mW}$, a modulation 
amplitude of $4 \mathrm{G}$, and a modulation frequency of $100 \mathrm{KHz}$. Inductively coupled plasma optical emission spectroscopy (ICP-OES) analysis was carried out using a Varian 720ES spectrometer.

\subsection{Catalytic Studies}

A typical example for the oxidation of benzyl alcohol by the Ru-Mn-Ce catalyst is as follows: A mixture of catalyst $(0.05 \mathrm{~g}, \mathrm{Ru} 0.03 \mathrm{mmol})$, benzyl alcohol $(4 \mathrm{mmol})$ and benzotrifluoride $(5 \mathrm{ml})$ was stirred in a $100 \mathrm{~mL}$ round-bottom flask equipped with a condenser. All reactions were performed under an oxygen atmosphere using an oxygen balloon. The reaction was initiated by immersing the flask in the oil bath kept at the reaction temperature, and then carried out with vigorous stirring for a certain time. Products were analyzed by a standardized gas chromatograph (GC 9560) with a SE-54 capillary column. For recyclability studies, the used catalyst was washed with water, followed by drying at $110^{\circ} \mathrm{C}$, and then subjected to the alcohol oxidation under the same conditions.

\section{Results and discussion}

\section{1. Catalyst characterization}

Fig.1 shows the XRD patterns of Mn-Ce, Co-Ce mixed oxides and corresponding Ru-Mn-Ce and Ru-Co-Ce catalysts calcined at different temperatures. As shown in Fig.1 (a-d), the diffraction peaks at $2 \theta=28.6,33.1,47.5$ and $56.3^{\circ}$ could be assigned to $\mathrm{CeO}_{2}$ (JCPDS: 43-1002), the intensive and sharp diffractions at $2 \theta=18.0,28.9,31.0,32.3,36.1,36.4,38.0,44.4,50.7,58.5$, 59.8 and $64.7^{\circ}$ can be primarily attributed to $\mathrm{Mn}_{3} \mathrm{O}_{4}$ (JCPDS: 24-0734), the peaks ascribed to the phases of $\mathrm{Mn}_{3} \mathrm{O}_{4}$ and $\mathrm{CeO}_{2}$ are obvious and the peaks corresponding to the $\mathrm{RuO}_{2}$ almost are invisible before the catalysts are calcined. With calcination the peaks corresponding to the $\mathrm{Mn}_{3} \mathrm{O}_{4}$ are weaker and new peaks assigned to $\mathrm{MnO}_{2}$ (JCPDS: 50-0866) appear, which indicates that most of the $\mathrm{Mn}_{3} \mathrm{O}_{4}$ has transformed to $\mathrm{MnO}_{2}$ after calcination. Meanwhile, the peaks corresponding to $\mathrm{RuO}_{2}$ (JCPDS: 40-1290) and $\mathrm{CeO}_{2}$ phases increased with the higher calcined temperature (especially at $500^{\circ} \mathrm{C}$ ), suggesting the $\mathrm{RuO}_{2}$ and $\mathrm{CeO}_{2}$ phases segregate and are isolated with the heat treatment. For Ru-Co-Ce catalysts shown in Fig.1 (e-h), the peaks corresponding to the $\mathrm{CeO}_{2}$ are more obvious than their Ru-Mn-Ce partners, the diffraction peaks at $2 \theta=20.2,38.9,50.6$ and $65.3^{\circ}$ could be assigned to $\mathrm{CoO}(\mathrm{OH})(\mathrm{JCPDS}: 07-0169)$. With calcination, the $\mathrm{CoO}(\mathrm{OH})$ phase vanishes and a new $\mathrm{Co}_{3} \mathrm{O}_{4}$ phase appears, with corresponding diffraction peaks at 31.3, 36.9, 59.4 and $65.2^{\circ}$ (JCPDS: 42-1467), however, the isolation of $\mathrm{RuO}_{2}$ phase is not obvious. 
Fig.2 shows the Raman spectra of Ru-Mn-Ce and Ru-Co-Ce catalysts before and after calcination. The $450 \mathrm{~cm}^{-1}$ peak corresponds to the $\mathrm{F}_{2 \mathrm{~g}}$ Raman active mode of $\mathrm{CeO}_{2}$ fluorite structure, due to the asymmetric breathing mode of the oxygen atoms around $\mathrm{Ce}^{4+}$ cations. This signal is markedly weaker for the catalyst calcined at $500^{\circ} \mathrm{C}$. None of the catalysts present any Raman peaks at $600 \mathrm{~cm}^{-1}$, suggesting the ceria is low in oxygen defects [16-17]. Two peaks located at 575 and $650 \mathrm{~cm}^{-1}$ are present due to $\mathrm{MnO}_{2}$, and there is an obvious increase in peak intensity when the catalyst was calcined at $500^{\circ} \mathrm{C}$ [18]. A signal at $525 \mathrm{~cm}^{-1}$ for Ru-Mn-Ce (500) catalysts, corresponding to the $\mathrm{E}_{\mathrm{g}}$ Raman active mode of $\mathrm{RuO}_{2}$ crystals, suggests the formation of a $\mathrm{RuO}_{2}$ phase [19]. For Ru-Co-Ce catalysts shown in Fig. 2 (c-d), the $\mathrm{F}_{2 \mathrm{~g}}$ Raman active mode of the $\mathrm{CeO}_{2}$ fluorite structure appears in the uncalcined catalysts and disappears after calcination to $500^{\circ} \mathrm{C}$. The signals at 470,510 and $675 \mathrm{~cm}^{-1}$ are attributed to the spinel structure of $\mathrm{Co}_{3} \mathrm{O}_{4}$ [20].
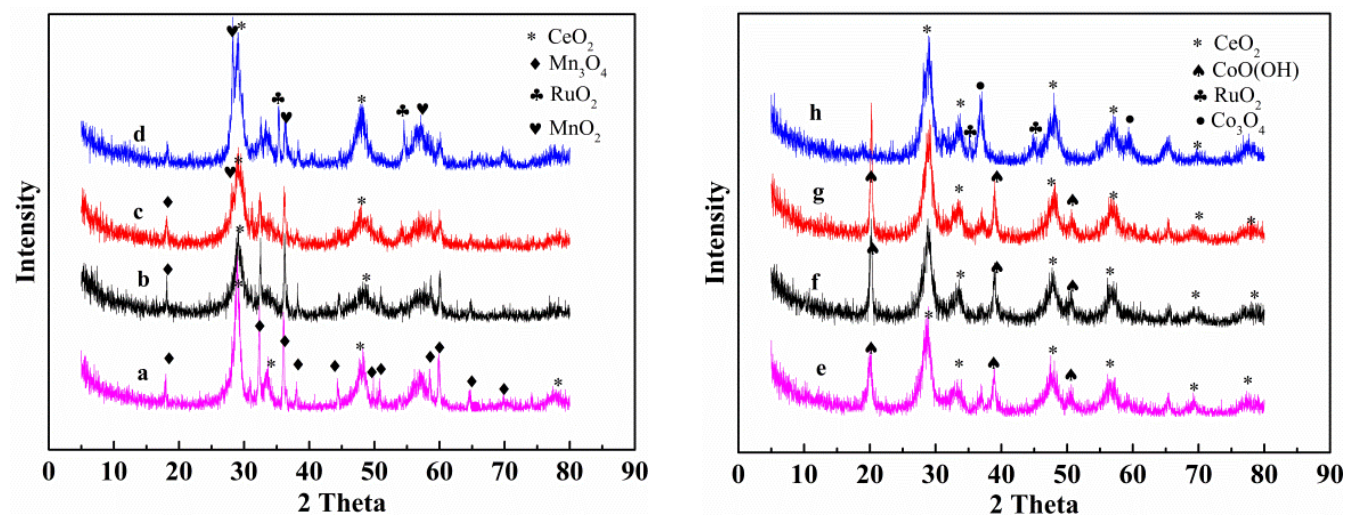

Fig.1 XRD patterns of catalysts (a) Mn-Ce, (b) Ru-Mn-Ce, (c) Ru-Mn-Ce (300), (d) Ru-Mn-Ce (500) and (e) Co-Ce, (f) Ru-Co-Ce, (g) Ru-Co-Ce (300), (h) Ru-Co-Ce (500).
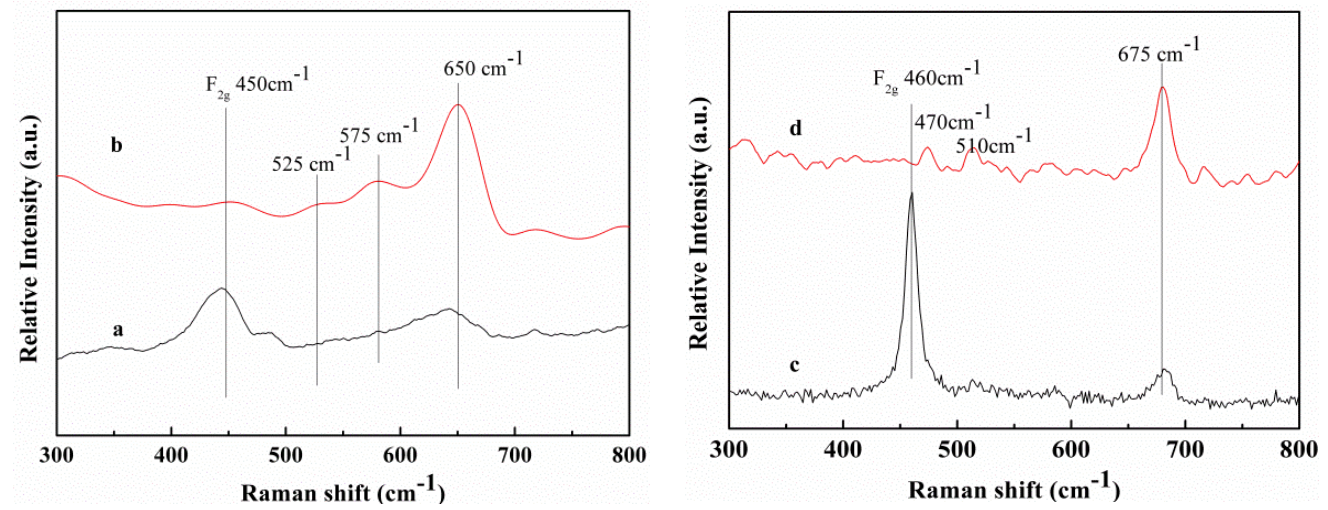

Fig.2 Raman spectra of catalysts (a) Ru-Mn-Ce; (b) Ru-Mn-Ce (500); (c) Ru-Co-Ce; (d) $\mathrm{Ru}-\mathrm{Co}-\mathrm{Ce}$ (500). 

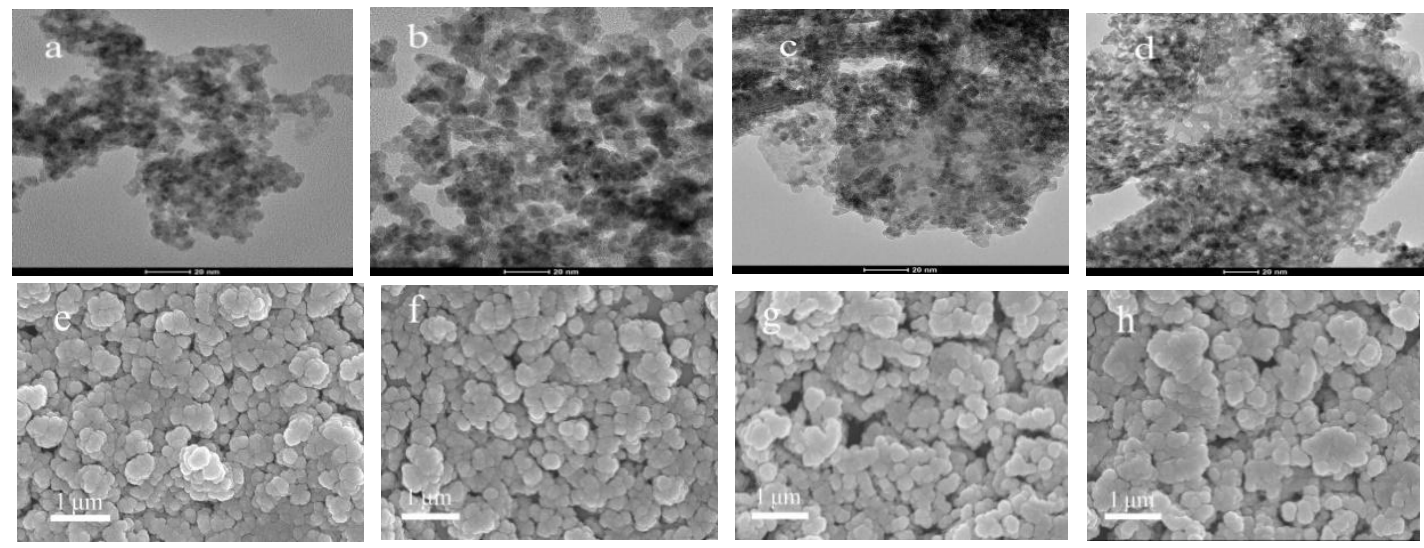

Fig.3 TEM images of (a) Ru-Mn-Ce, (b) Ru-Mn-Ce (500), (c) Ru-Co-Ce, (d) Ru-Co-Ce (500) catalysts and SEM images of (e) Ru-Mn-Ce, (f) Ru-Mn-Ce (500), (g) Ru-Co-Ce, (h) Ru-Co-Ce (500) catalysts

Fig. 3 shows TEM and SEM images of Ru-Mn-Ce and Ru-Co-Ce catalysts before and after calcination. All the samples have platelet morphologies with $200 \mathrm{~nm}$ sizes on average, with relatively low aggregation. Both TEM and SEM images do not reveal a significant difference before and after calcination for the morphology of these four catalysts (Fig.3 a-d, e-h), although their phases segregate. The size changes of $\mathrm{Ru}$ species are not obvious (black flakes), which maintained at 5-8 $\mathrm{nm}$ before and after calcination. Meanwhile, the dispersion of $\mathrm{Ru}, \mathrm{Mn}(\mathrm{Co}), \mathrm{Ce}$ and $\mathrm{O}$ atoms in the catalyst was analyzed by STEM-elemental mapping (Fig. S1-S4). The mapping of catalysts before calcination indicated that each of the $\mathrm{Ru}, \mathrm{Mn}(\mathrm{Co})$ and $\mathrm{O}$ species were homogeneously dispersed. When the $\mathrm{Ru}-\mathrm{Mn}-\mathrm{Ce}$ and $\mathrm{Ru}-\mathrm{Co}-\mathrm{Ce}$ catalysts were calcined, the elemental dispersion changed, with the concentration of Ce strengthening and concentrations of $\mathrm{Ru}$ and $\mathrm{Mn}$ decreasing for Ru-Mn-Ce (500). In the cobalt-containing samples, the concentration of $\mathrm{Ce}$ decreased and concentrations of $\mathrm{Ru}$ and $\mathrm{Co}$ increased. This might be attributed to their different interactions when the phases changed (See XPS Ru 2p section).

For both material systems the BET surface area decreases slightly after calcination. The BET surface areas of $\mathrm{Ru}-\mathrm{Mn}-\mathrm{Ce}$ and $\mathrm{Ru}-\mathrm{Mn}-\mathrm{Ce}$ (500) are 85 and $38 \mathrm{~m}^{2} / \mathrm{g}$, respectively, and the Ru-Co-Ce and Ru-Co-Ce (500) show surface areas of 77 and $58 \mathrm{~m}^{2} / \mathrm{g}$, respectively, this shows the Ru-Co-Ce catalysts have better resistance to high temperature calcination. Fig.S5 shows the nitrogen adsorption-desorption isotherms of the four catalysts, all of which are Type H3 hysteresis loops, which are attributed to the aggregation of nanoparticles giving rise to slit-shaped pores [21]. 

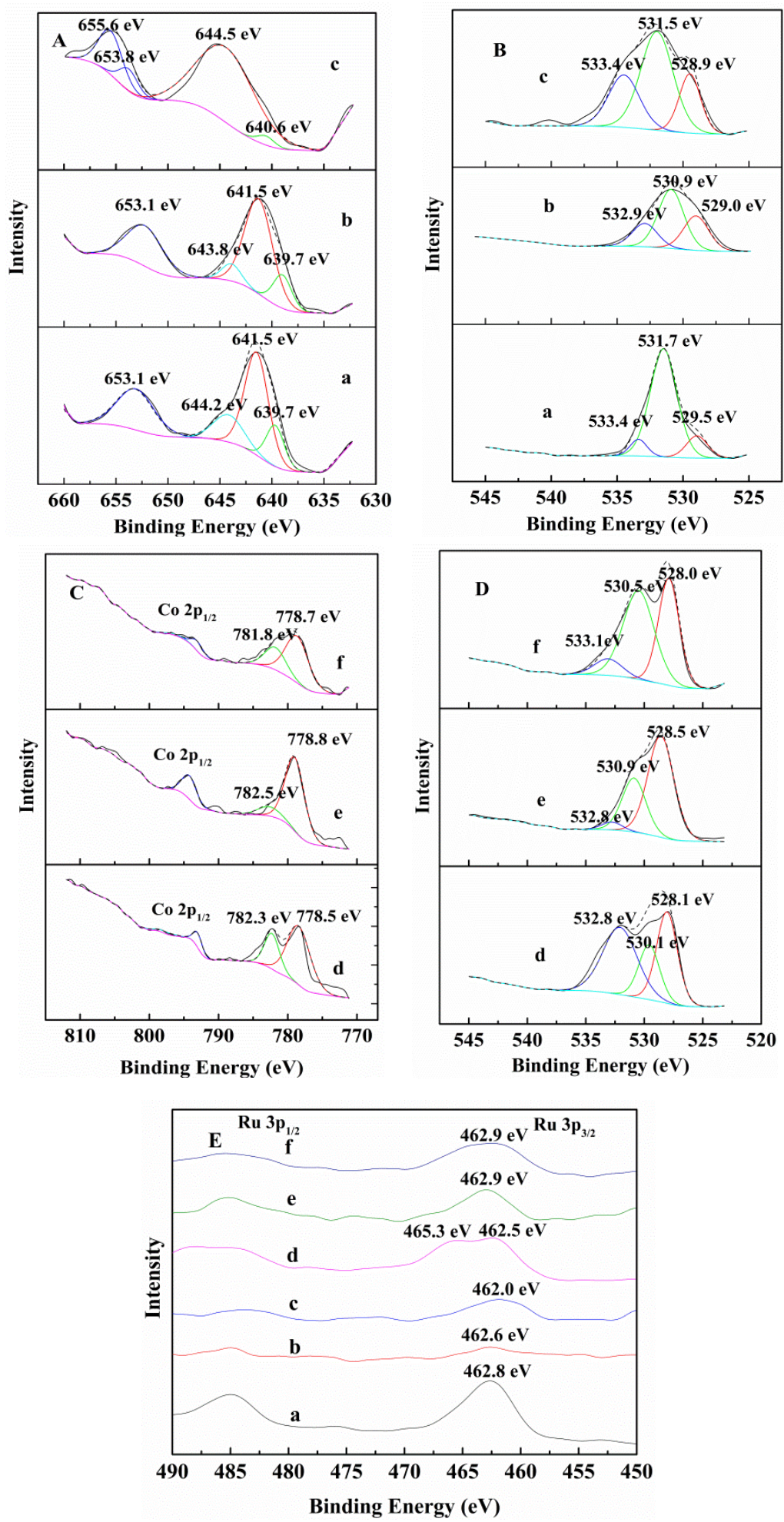

Fig.4 XPS spectra of (A) Mn 2p, (B) O 1s of catalysts (a) Ru-Mn-Ce, (b) Ru-Mn-Ce (300), (c) Ru-Mn-Ce (500) ; (C) Co 2p, (D) O 1s of catalysts (d) Ru-Co-Ce, (e) Ru-Co-Ce (300), (f) Ru-Co-Ce (500); (E) Ru 2p of (a) Ru-Mn-Ce, (b) Ru-Mn-Ce (300), (c) Ru-Mn-Ce (500), (d) Ru-Co-Ce, (e) Ru-Co-Ce (300) and (f) Ru-Co-Ce (500) catalysts.

Fig.4 shows the XPS spectra of Ru-Mn-Ce and Ru-Co-Ce catalysts before and after calcination. 
Deconvolution peak fitting was performed on $M n 2 p_{3 / 2}$ spectra aiming to determine the characteristic peaks of $\mathrm{Mn}$ species (Fig.4A), including surface $\mathrm{Mn}^{2+}(639.8-640.8 \mathrm{eV}), \mathrm{Mn}^{3+}$ $(641.8-642.3 \mathrm{eV})$ and $\mathrm{Mn}^{4+}(644.0-644.5 \mathrm{eV})$ [22]. For the Ru-Mn-Ce catalyst, the spectrum of $\mathrm{Mn}$ $2 p$ is one asymmetrical signal which can be decomposed into three components at $\mathrm{BE}=639.7$, 641.5 and $644.2 \mathrm{eV}$ which are assigned to the surface $\mathrm{Mn}^{2+}, \mathrm{Mn}^{3+}, \mathrm{Mn}^{4+}$ species, with $\mathrm{Mn}^{3+}$ species being the main species. The content of surface $\mathrm{Mn}^{3+}$ was $44.0 \%$ in the Ru-Mn-Ce Catalyst as synthesized. For the sample calcined to 300 and $500^{\circ} \mathrm{C}$ catalyst, the Mn was oxidized to $\mathrm{Mn}^{4+}$ species, with the content of surface $\mathrm{Mn}^{4+}$ reaching $52.2 \%$ and $73 \%$, respectively. This result is consistent with the XRD analysis showing that $\mathrm{MnO}_{2}$ becomes the main manganese phase after calcination. The Co $2 \mathrm{p}$ peaks appear at 778.5 and $782.3 \mathrm{eV}$ are corresponding to a significant amount of $\mathrm{Co}^{2+}$ or $\mathrm{Co}^{3+}$ for Ru-Co-Ce catalysts (Fig.4C), the valence state of the cobalt remained almost unchanged after calcination. It has a $1.5 \mathrm{eV}$ negative shift comparing with the $780.0 \mathrm{eV}$ reported for $\mathrm{Ru} / \mathrm{Co}_{3} \mathrm{O}_{4}$ catalyst in the literatures [23-24], which indicates a strong interaction between the Ru-Co-Ce oxides.

The spectra of O 1s of Ru-Mn-Ce and Ru-Mn-Ce (500) catalysts are described in Fig. 4B. XPS of oxygen species are complicated for mixed oxides, and peaks are generally deconvoluted into contributions from surface lattice oxygen $\left(\mathrm{O}_{\text {latt }}, \mathrm{O}^{2-}\right)$, adsorbed oxygen $\left(\mathrm{O}_{\text {ads }}, \mathrm{O}^{2-}, \mathrm{O}_{2}{ }^{2-}\right.$, or $\left.\mathrm{O}^{-}\right)$, and adsorbed $\mathrm{OH}$ groups or molecular water on the surface of the catalysts $\left(\mathrm{O}_{\text {sur }}\right)$. The $\mathrm{O} 1 \mathrm{~s}$ spectra at $\mathrm{BE}=528.0-529.5,530.0-531.9,532.8-534.6 \mathrm{eV}$ are assigned to $\mathrm{O}_{\text {latt, }}, \mathrm{O}_{\text {ads }}$, and $\mathrm{O}_{\text {sur }}$ species [25-26], respectively. For Ru-Mn-Ce, Ru-Mn-Ce (300) and Ru-Mn-Ce (500) catalysts (Fig. 4D), the $\mathrm{O} 1 \mathrm{~s}$ spectra can be fit with three components and the content of $\mathrm{O}_{\text {ads }}$ was $79.3,50.9$ and $42.6 \%$, respectively (the content decreased after calcination). The content of $\mathrm{O}_{\text {ads }}$ was lower in the cobalt containing catalysts, with $21.3,31.5$ and $57.6 \%$ for Ru-Co-Ce, Ru-Co-Ce (300) and Ru-Co-Ce (500) catalysts (the contents increased after calcination). Typically, a higher $\mathrm{O}_{\text {ads }}$ concentration is considered beneficial for improving catalytic performance as the surface adsorbed oxygen can attack an organic molecule [27].

XPS analysis of the Ru component of the catalysts (Fig.4E) is performed on the Ru $3 p_{3 / 2}$ located near $462.5 \mathrm{eV}$. For the Ru-Co-Ce catalyst, the peak due to $\mathrm{Ru} 3 \mathrm{p}_{3 / 2}$ is composed of two doublets (462.5 and $465.3 \mathrm{eV}$ ) with the former $1.0 \mathrm{eV}$ higher than that of bulk $\mathrm{Ru}(0)(461.5 \mathrm{eV}$ ), suggesting $\mathrm{RuO}_{2}$ is the dominant species [28]. The peak centered at $466.5 \mathrm{eV}$ can be assigned to 
$\mathrm{RuO}_{2} \bullet \mathrm{xH}_{2} \mathrm{O}$ [29], while the $\mathrm{Ru} 3 \mathrm{p}_{3 / 2}$ peak at $465.8 \mathrm{eV}$ disappears and $462.5 \mathrm{eV}$ together moves to $462.9 \mathrm{eV}$ for Ru-Co-Ce (300) and Ru-Co-Ce (500) catalyst, which suggests stronger interactions exist between the $\mathrm{RuO}_{2}$ and $\mathrm{Co}_{3} \mathrm{O}_{4}-\mathrm{CeO}_{2}$ mixed oxides after calcination. For the Ru-Mn-Ce, Ru-Mn-Ce (300) and Ru-Mn-Ce (500) catalysts, the BEs of Ru 3p $\mathrm{p}_{3 / 2}$ shifted gradually from 462.8 to $462.0 \mathrm{eV}$, and intensity of the peak is weaker, it is because that the manganese species transforms from $\mathrm{Mn}^{3+}$ to $\mathrm{Mn}^{4+}$, and part of electrons flows to ruthenium species, thus the interactions between the $\mathrm{RuO}_{2}$ and $\mathrm{Mn}$-Ce mixed oxides weaken when the $\mathrm{Mn}_{3} \mathrm{O}_{4}$ phase transforms to $\mathrm{MnO}_{2}$ and then $\mathrm{MnO}_{2}$ phase is isolated. Therefore, the $\mathrm{BE}$ of $\mathrm{Ru} 3 \mathrm{p}_{3 / 2}$ at $462.8-462.9$ $\mathrm{eV}$ should be due to the strong interactions between the $\mathrm{RuO}_{2}$ and other mixed oxides.

TPR experiments were carried out in order to study the redox properties of $\mathrm{Mn}-\mathrm{Ce}, \mathrm{Co}-\mathrm{Ce}$ mixed oxides and corresponding Ru-Mn-Ce and Ru-Co-Ce catalysts calcined at different temperatures (Fig.5). The temperature at peak maximum and the integral $\mathrm{H}_{2}$ consumption in the temperature range $50-800^{\circ} \mathrm{C}$ is summarized in Table 1 . The peak under $150^{\circ} \mathrm{C}$ is assigned to the reduction of $\mathrm{RuO}_{2}$ to $\mathrm{Ru}^{0}$ [29], however, the peak is not obvious, which is might be due to its low content. The main reduction peaks of ceria appear between 290-465 ${ }^{\circ} \mathrm{C}$ [30] (this peak is not obvious in our catalysts) and the peak at $205-385^{\circ} \mathrm{C}$ should be assigned to the reduction of $\mathrm{MnOx}$ [31] (Fig.5 a, b, c, d). It is known cobalt-oxide reduction occurs in two steps- $\mathrm{Co}^{3+}$ to $\mathrm{Co}^{2+}$, between 200 and $300^{\circ} \mathrm{C}$, and from $\mathrm{Co}^{2+}$ to $\mathrm{Co}^{0}$ at $325^{\circ} \mathrm{C}$ [32]. For our Ru-Co-Ce catalysts, the reduction temperature of the former decreased from 153 to $143^{\circ} \mathrm{C}$ and the latter decreased from 300 to $247^{\circ} \mathrm{C}$ with increasing calcination temperature (Fig.5 e, f, g, h), obviously, the reduction temperature shifted to a lower temperature as compared to pure $\mathrm{Co}_{3} \mathrm{O}_{4}$ [24], indicating that the addition of Ru markedly facilitated the reduction of cobalt species. For our Ru-Mn-Ce catalysts, the reduction peaks at $122-285^{\circ} \mathrm{C}$ should be due to the reduction of $\mathrm{MnO}_{2}$ to $\mathrm{Mn}_{3} \mathrm{O}_{4}$ and the reduction peaks at $240-385^{\circ} \mathrm{C}$ should be due to the reduction of $\mathrm{Mn}_{3} \mathrm{O}_{4}$ to $\mathrm{MnO}$, the reduction temperatures shifted to a lower temperature after $\mathrm{RuO}_{2}$ mixed with Mn-Ce oxides, this indicates that the addition of $\mathrm{Ru}$ markedly facilitates the reduction of manganese species. The peaks for Mn-Ce, Ru-Mn-Ce, and Ru-Mn-Ce (300) are very weak; this shows the $\mathrm{MnO}_{2}$ phase is less present in these catalysts. However, when the catalyst was calcined at $500^{\circ} \mathrm{C}$, a high reduction peak appeared at $205^{\circ} \mathrm{C}$, this indicates that $\mathrm{MnO}_{2}$ has become the dominant phase in $\mathrm{Ru}-\mathrm{Mn}-\mathrm{Ce}$ (500) catalyst, which is in agreement with other data [31]. Meanwhile, the reduction peaks of 
$\mathrm{RuO}_{2}$ phase changed from 80 to $127^{\circ} \mathrm{C}$ for $\mathrm{Ru}-\mathrm{Mn}-\mathrm{Ce}$ catalysts and from 105 to $113^{\circ} \mathrm{C}$ for $\mathrm{Ru}-\mathrm{Co}-\mathrm{Ce}$ catalysts with the increasing calcination temperature, respectively. Over all, whether they are Ru-Co-Ce or Ru-Mn-Ce catalysts, the reduction temperature increases with the higher calcination temperature, obviously, this experiment highlights different interactions between the components in mixed oxides, which results in shifting of the reduction peaks. The stronger the interaction between the oxides, the higher the initial temperature of reduction [33-34]. Differently, as the $\mathrm{MnO}_{2}$ phase was isolated for Ru-Mn-Ce (500) catalyst, the interaction between the mixed oxides weakened. $\mathrm{H}_{2}$ consumption significantly increased when $\mathrm{RuO}_{2}$ mixed with Co-Ce or Mn-Ce oxides. For the Ru-Mn-Ce catalysts, the $\mathrm{H}_{2}$ consumption decreased significantly with the increase of the calcination temperature, while the decrease of $\mathrm{H}_{2}$ consumption was moderate with the higher calcination temperature for the Ru-Co-Ce catalysts. The decreased $\mathrm{H}_{2}$ consumption for Ru-Mn-Ce catalysts after calcination may be due to reduced content of adsorbed oxygen. The experimental results support the theory we have proposed of the interactions change between ruthenium oxides and $\mathrm{Co}(\mathrm{Mn})$-Ce mixed oxides before and after calcination in this system.

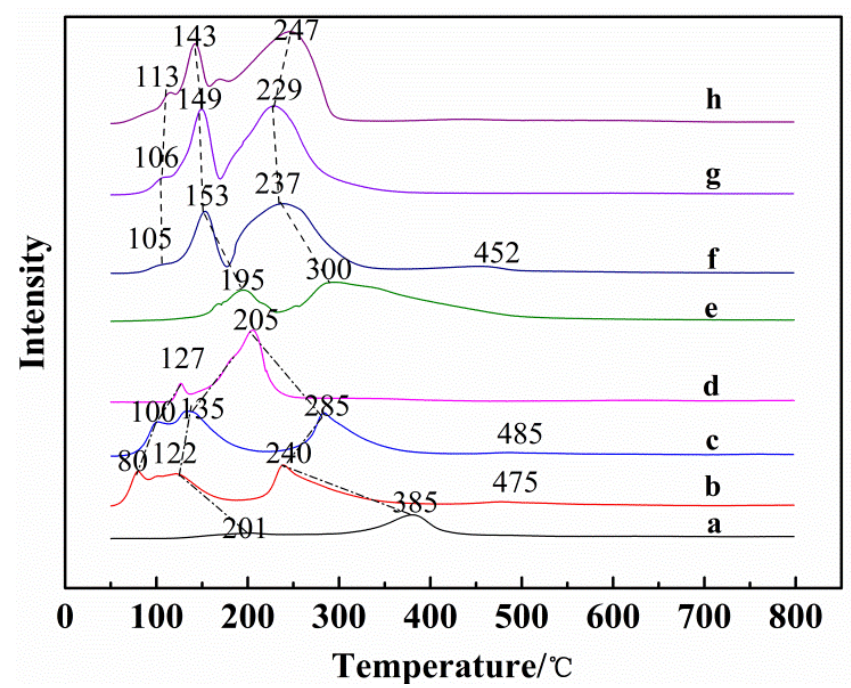

Fig.5 H $\mathrm{H}_{2}$-TPR profiles of (a) Mn-Ce, (b) Ru-Mn-Ce, (c) Ru-Mn-Ce (300), (d) Ru-Mn-Ce (500), (e) Co-Ce, (f) Ru-Co-Ce, (g) Ru-Co-Ce (300) and (h) Ru-Co-Ce (500) catalysts.

The transformation of phases after calcination also can be approved by EPR spectra. As seen from Fig.6, the sextet of hyperfine lines of higher amplitude arises from $\mathrm{Mn}^{4+}$ species for Ru-Mn-Ce (500) catalyst [35], which further testify that the $\mathrm{MnO}_{2}$ phase segregates from the composite after calcination. However, we cannot find the obvious signal of any $\mathrm{Co}^{2+} / \mathrm{Co}^{3+}$ species for $\mathrm{Ru}-\mathrm{Co}-\mathrm{Ce}$ (500) catalyst; this illustrates no change of lone pair electron after calcination. 

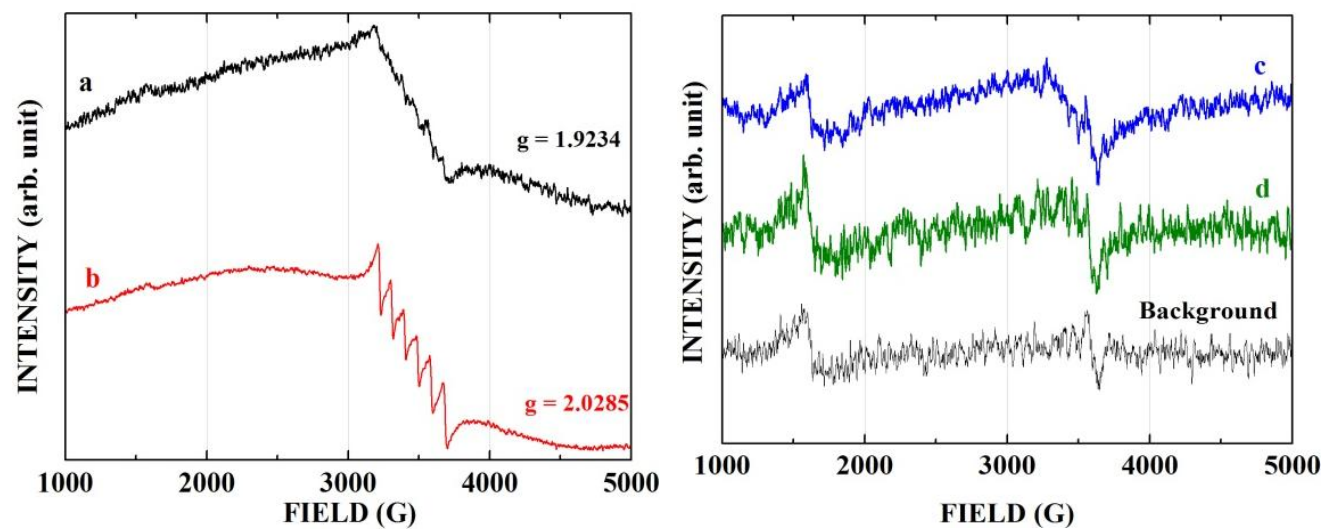

Fig.6 EPR spectra of samples at $300 \mathrm{~K}$ (a) Ru-Mn-Ce, (b) Ru-Mn-Ce (500), (c) Ru-Co-Ce and (d) Ru-Co-Ce (500) catalysts.

Table 1 Characterization results for $\mathrm{Ru}-\mathrm{Mn}-\mathrm{Ce}$ and $\mathrm{Ru}-\mathrm{Co}-\mathrm{Ce}$ catalysts in the present study

\begin{tabular}{|c|c|c|c|c|c|c|c|c|}
\hline \multirow[t]{2}{*}{ Catalyst } & \multirow{2}{*}{$\begin{array}{l}\text { BET SA } \\
\left(\mathrm{m}^{2} / \mathrm{g}\right)\end{array}$} & \multirow{2}{*}{$\begin{array}{l}\mathrm{H}_{2} \text { consumption } \\
\left(\mathrm{cm}^{3} / \mathrm{g}\right)\end{array}$} & \multirow{2}{*}{$\begin{array}{l}\mathrm{Ru} 3 \mathrm{p}_{3 / 2} \\
(\mathrm{eV})\end{array}$} & \multirow{2}{*}{$\begin{array}{l}\mathrm{Mn} \\
2 \mathrm{p}_{3 / 2} \\
(\mathrm{eV})\end{array}$} & \multirow{2}{*}{$\begin{array}{l}\text { Co } 2 p_{3 / 2} \\
(\mathrm{eV})\end{array}$} & \multicolumn{3}{|c|}{ Reduction temperature $/{ }^{\circ} \mathrm{C}$} \\
\hline & & & & & & $\mathrm{RuO}_{2}$ & $\mathrm{MnOx}$ & $\mathrm{CoOx}$ \\
\hline $\mathrm{Mn}-\mathrm{Ce}$ & 76.2 & $\begin{array}{l}30.1 \\
(4.8+25.3)\end{array}$ & l & I & l & I & $\begin{array}{l}201 \\
385\end{array}$ & l \\
\hline $\mathrm{Ru}-\mathrm{Mn}-\mathrm{Ce}$ & 84.7 & $\begin{array}{l}101.8 \\
(3.2+57.7+40.9)\end{array}$ & 462.8 & $\begin{array}{l}639.7 \\
641.5 \\
644.2\end{array}$ & l & 80 & $\begin{array}{l}122 \\
240\end{array}$ & l \\
\hline Ru-Mn-Ce (300) & 61.8 & $\begin{array}{l}89.3 \\
(2.9+39.6+46.8)\end{array}$ & 462.6 & $\begin{array}{l}639.7 \\
641.5 \\
643.8\end{array}$ & l & 100 & $\begin{array}{l}135 \\
285\end{array}$ & l \\
\hline Ru-Mn-Ce (500) & 37.9 & $\begin{array}{l}61.0 \\
(2.7+58.3)\end{array}$ & 462.0 & $\begin{array}{l}640.6 \\
644.5\end{array}$ & / & 127 & 205 & l \\
\hline $\mathrm{Co}-\mathrm{Ce}$ & 68.5 & $\begin{array}{l}103.3 \\
(21.5+81.8)\end{array}$ & I & / & / & l & / & $\begin{array}{l}195 \\
300\end{array}$ \\
\hline $\mathrm{Ru}-\mathrm{Co}-\mathrm{Ce}$ & 76.7 & $\begin{array}{l}167.7 \\
(5.9+41.2+120.6)\end{array}$ & $\begin{array}{l}462.5 \\
465.3\end{array}$ & I & $\begin{array}{l}778.5 \\
782.3\end{array}$ & 105 & l & $\begin{array}{l}153 \\
237\end{array}$ \\
\hline Ru-Co-Ce (300) & 62.4 & $\begin{array}{l}152.2 \\
(5.6+38.9+107.7)\end{array}$ & 462.9 & I & $\begin{array}{l}778.8 \\
782.5\end{array}$ & 106 & I & $\begin{array}{l}149 \\
229\end{array}$ \\
\hline Ru-Co-Ce (500) & 58.4 & $\begin{array}{l}137.8 \\
(6.4+34.8+96.6)\end{array}$ & 462.9 & I & $\begin{array}{l}778.7 \\
781.5\end{array}$ & 113 & l & $\begin{array}{l}143 \\
247\end{array}$ \\
\hline
\end{tabular}

\section{2. Catalyst activity}

The oxidation of benzyl alcohol was examined as a model reaction over the four catalysts (Table 2). The Ru-Mn-Ce catalyst gave $100 \%$ conversion initially, however the activity decreases to only $19.4 \%$ when the Ru-Mn-Ce catalyst was replaced by Ru-Mn-Ce (500). The Ru-Co-Ce catalyst gave $78.2 \%$ conversion initially, which they improved to $92.3 \%$ when the calcined catalyst (500) was used (entries 1-6, Table 2). A solvent study was run using different solvents 
including toluene, N, N-dimethylformamide, dimethyl sulfoxide, acetonitrile, and benzotrifluoride (entries 7-10, Table 2). Of these reaction media tested, benzotriflouride performed the best of the studied reaction solvents, and was used in further tests.

To study the role of $\mathrm{Ru}, \mathrm{Mn}-\mathrm{Ce}$ and $\mathrm{Co}-\mathrm{Ce}$ mixed oxides were prepared by the same procedure, and the reaction yielded $4.6 \%$ and $7.2 \%$ conversion of benzyl alcohol, respectively (entries 11-12, Table 2). This indicated that the Ru component was responsible for the catalytic activity. To further illustrate the mixed-oxide dependence on activity, binary $\mathrm{Ru}-\mathrm{Co}_{3} \mathrm{O}_{4}, \mathrm{Ru}-\mathrm{CeO}_{2}$ and $\mathrm{Ru} / \mathrm{MnO}_{2}$ catalysts were prepared under the same conditions (entries 13-15, Table 2), and these systems gave $57.2 \%, 44.8 \%$ and $44.6 \%$ conversion of benzyl alcohol. This suggests that the use of binary oxides in addition to the ruthenium component yield a high oxidative catalytic activity than the single component alone.

Table 2 Aerobic oxidation of benzyl alcohol over different catalysts ${ }^{a}$

\begin{tabular}{|c|c|c|c|c|}
\hline Entry & Catalyst & Solvent & $\begin{array}{c}\text { Conversion }^{b} \\
(\%)\end{array}$ & $\begin{array}{c}\text { Benzaldehyde Selectivity } \\
\qquad(\%)^{b}\end{array}$ \\
\hline 1 & $\mathrm{Ru}-\mathrm{Mn}-\mathrm{Ce}$ & Benzotrifluoride & 100 & 100 \\
\hline 2 & Ru-Mn-Ce (300) & Benzotrifluoride & 66.4 & 100 \\
\hline 3 & Ru-Mn-Ce (500) & Benzotrifluoride & 19.4 & 100 \\
\hline 4 & $\mathrm{Ru}-\mathrm{Co}-\mathrm{Ce}$ & Benzotrifluoride & 78.2 & 100 \\
\hline 5 & Ru-Co-Ce (300) & Benzotrifluoride & 88.4 & 100 \\
\hline 6 & $\mathrm{Ru}-\mathrm{Co}-\mathrm{Ce}(500)$ & Benzotrifluoride & 92.3 & 100 \\
\hline 7 & $\mathrm{Ru}-\mathrm{Mn}-\mathrm{Ce}$ & Toluene & 96.1 & 100 \\
\hline 8 & $\mathrm{Ru}-\mathrm{Mn}-\mathrm{Ce}$ & $\mathrm{N}, \mathrm{N}$-dimethylformamide & 27.9 & 100 \\
\hline 9 & $\mathrm{Ru}-\mathrm{Mn}-\mathrm{Ce}$ & Dimethyl sulfoxide & 38.5 & 100 \\
\hline 10 & $\mathrm{Ru}-\mathrm{Mn}-\mathrm{Ce}$ & Acetonitrile & 10.8 & 100 \\
\hline 11 & $\mathrm{Mn}-\mathrm{Ce}$ & Benzotrifluoride & 4.6 & 100 \\
\hline 12 & $\mathrm{Co}-\mathrm{Ce}$ & Benzotrifluoride & 7.2 & 100 \\
\hline 13 & $\mathrm{Ru}-\mathrm{Co}_{3} \mathrm{O}_{4}$ & Benzotrifluoride & 57.2 & 100 \\
\hline 14 & $\mathrm{Ru}-\mathrm{CeO}_{2}$ & Benzotrifluoride & 44.8 & 100 \\
\hline 15 & $\mathrm{Ru}-\mathrm{MnO}_{2}$ & Benzotrifluoride & 44.6 & 100 \\
\hline
\end{tabular}


${ }^{a}$ Reaction conditions: catalyst $0.05 \mathrm{~g}(\mathrm{Ru}: 0.03 \mathrm{mmol})$, benzyl alcohol $4 \mathrm{mmol}$, solvent $5 \mathrm{~mL}$, oxygen balloon, $60^{\circ} \mathrm{C}, 6$ h. ${ }^{b}$ Determined by GC.

To further understand catalytic activity, the oxidation of various alcohols was examined over the $\mathrm{Ru}-\mathrm{Mn}-\mathrm{Ce}$ catalyst using benzotrifluoride as solvent at $60^{\circ} \mathrm{C}$, and the results are shown in Table 3 . All the benzylic and allylic alcohols show high yields for the oxidative dehydrogenation (entries 1-7, Table 3), transforming to the corresponding aldehydes in higher than $96 \%$ yield. The primary aliphatic alcohols were readily oxidized to aldehydes in high yields with a longer reaction time, and aliphatic secondary alcohols had higher catalytic performance than the primary ones, which shows the promotion of the electron density of substrates in this reaction (entries 8-9, Table 3). When the Ru-Mn-Ce catalysts were used in the oxidation of heterocyclic alcohols, thiophene-2-methanol, and furan-2-methanol could be oxidized to corresponding aldehyde in short time, but pyridine-2-methanol showed low reactivity for oxidative dehydrogenation, reaching only $52 \%$ yield with an 18 hour reaction time (entries 10-12, Table 3). Cyclohexanol was effectively oxidized to cyclohexanone in $12 \mathrm{~h}$ (entry 13, Table 3). To demonstrate recyclability of the catalyst, the catalyst was used sequentially in five reactions and the Ru-Mn-Ce catalyst gave $98 \%$ yield for the fifth use. Leaching of Ru was tested by hot filtration, and induced coupled plasma techniques (ICP) revealed no ruthenium in the filtrate.

Table 3 Aerobic oxidation of different alcohols catalyzed by Ru-Mn-Ce catalyst ${ }^{a}$

\begin{tabular}{|c|c|c|c|c|c|}
\hline Entry & Time (h) & Substrate & Product & Conversion $(\%)^{\mathrm{b}}$ & Yield $(\%)^{\mathrm{b}}$ \\
\hline 1 & 4 & & & 100 & 100 \\
\hline $2^{\mathrm{c}}$ & 4 & & & 98 & 98 \\
\hline 3 & 3 & & & 100 & 100 \\
\hline 4 & 0.5 & & & 100 & 100 \\
\hline 5 & 1 & & & 96 & 96 \\
\hline 6 & 4 & & $\mathrm{HO}$ & 98 & 98 \\
\hline 7 & 2 & & $C H$ & 100 & 100 \\
\hline 8 & 20 & & & 87 & 87 \\
\hline
\end{tabular}




(2)

\section{3. Discussion}

The Ru-Mn-Ce catalysts showed poor performance after they were calcined, while Ru-Co-Ce catalysts showed better performance after they were calcined. For Ru-Mn-Ce catalysts, the obvious loss of catalytic property is due to the change of phase. All characterization techniques showed that the $\mathrm{Mn}_{3} \mathrm{O}_{4}$ phase was transformed to $\mathrm{MnO}_{2}$ after the $\mathrm{Ru}-\mathrm{Mn}$-Ce catalyst was calcined at $500^{\circ} \mathrm{C}$, and this change of Mn valence results in a more loose distribution (Fig.S1, S2). Through the formation of Mn-Ce mixed oxides by the addition of Ce, a synergistic interaction between Mn and $\mathrm{Ce}$ oxides can be interpreted as an oxygen transfer mechanism. $\mathrm{CeO}_{2}$ may act as an oxygen reservoir, transferring oxygen from the oxygen atmosphere to the $\mathrm{Ru}$ and $\mathrm{MnO}_{\mathrm{x}}$, which realizes the effective activation of molecular oxygen [36-37]. However, this transfer of oxygen is based on good-conditional Mn-Ce mixed oxides as a pre-condition; we propose this oxygen transfer mechanism has been blocked when $\mathrm{MnO}_{2}$ segregates from the composite due to increased valence [38], this segregation also can be approved by EPR and TPR data.

For $\mathrm{Ru}-\mathrm{Co}-\mathrm{Ce}$ catalysts, the increase of catalytic activity is due to the change of the crystalline phase of cobalt. All characterization techniques (XRD, Raman and XPS) show $\mathrm{CoO}(\mathrm{OH})$ was transformed to $\mathrm{Co}_{3} \mathrm{O}_{4}$ after the $\mathrm{Ru}-\mathrm{Co}-\mathrm{Ce}$ catalyst was calcined at $500^{\circ} \mathrm{C}$. The change of $\mathrm{Co}$ valence leads to a denser distribution (Figs. S3, S4) opposite to the Ru-Mn-Ce catalysts, and stronger interactions were obtained when the $\mathrm{CoO}(\mathrm{OH})$ phase was transformed to $\mathrm{Co}_{3} \mathrm{O}_{4}$. This may strengthen synergistic interactions between Co and Ce oxides (approved by the XPS and TPR test), further enhancing the oxygen transfer mechanism. This conclusion also can be drawn from 
the XPS O 1s data, as the contents of $\mathrm{O}_{\text {ads }}$ for Ru-Mn-Ce catalysts decrease after calcination, which may block oxygen transfer, while the contents of $\mathrm{O}_{\text {ads }}$ for $\mathrm{Ru}-\mathrm{Co}-\mathrm{Ce}$ and $\mathrm{Ru}-\mathrm{Co}-\mathrm{Ce}$ (500) catalysts alternatively increase and intensify the oxygen transfer.

From the reaction results, the activity is principally due to the $\mathrm{RuO}_{2}$, as evidenced by the lower conversions of the ruthenium-free mixed oxides. The activation and transfer of molecular oxygen to the ruthenium is likely due to the mixed oxides in the composite. Highly dispersed $\mathrm{RuO}_{2}$ nanocrystals agglomerated due to high-temperature calcination whether for Ru-Mn-Ce (500) or $\mathrm{Ru}-\mathrm{Co}-\mathrm{Ce}$ (500) catalyst; however, the results obtained from them are different. This difference is mainly due to phase separation of the former leading to blockage of oxygen transfer and the agglomeration of $\mathrm{RuO}_{2}$ is not obvious even if the catalyst is calcined (Figs. S2 and S4). This different phase separation also can be approved by the change of BET surface area and $\mathrm{H}_{2}$ consumption when all the catalysts are calcined.

\section{Conclusions}

Two kinds of ternary mixed oxides, $\mathrm{Ru}-\mathrm{Mn}-\mathrm{Ce}$ and $\mathrm{Ru}-\mathrm{Co}-\mathrm{Ce}$, were prepared by a co-precipitation method and used in the aerobic oxidation of alcohols to their corresponding aldehydes (ketones). Based on the characterization data, the interactions between ruthenium oxides and Mn-Ce mixed oxides weakened, while the opposite was observed in the cobalt-containing system after they were calcined. The decreased interactions between Mn-Ce and ruthenium (oxide) decreased the content of adsorbed oxygen and blocked oxygen transfer, while the heat treatment of the Ru-Co-Ce catalyst increased the content of adsorbed oxygen and promoted oxygen transfer. Under optimal reaction conditions, various kinds of alcohols were oxidized with high yields over Ru-Mn-Ce catalyst. The results also showed ruthenium oxide dispersed in the mixed oxides plays a key role in this reaction. The interactions between $\mathrm{Ru}$ oxide and Mn-Ce oxides as well as the higher concentration of adsorbed oxygen are especially important in the catalytic performance of these catalysts.

\section{Acknowledgements}

This work is financially supported by the National Natural Science Foundation of China (21303085), the Natural Science Foundation of Jiangsu Province (BK20130901, BK20130930), the Jiangsu Government Scholarship for Overseas Studies (JS-2014040, JS-2014060), the Program to Cultivate Outstanding Young Key Teachers of Nanjing Normal University and the 
Priority Academic Program Development of Jiangsu Higher Education Institutions. SLS acknowledges the support of the US Department of Energy, Office of Basic Energy Sciences,

Division of Chemical, Biological and Geological Sciences under grant DE-FG02-86ER13622.A000.

\section{References}

[1] L.M.D.R.S. Martins, A.P.C. Ribeiro, S.A.C. Carabineiro, J.L. Figueiredoc, A.J.L. Pombeiro, Dalton Trans., 45 (2016) 6816-6819.

[2] ten Brink, G.-J., Arends, I. W. C. E. \& Sheldon, R. A. Green, Science, 287 (2000) 1636-1639.

[3] Enache, D. et al. Science, 311 (2006) 362-365.

[4] K. Yamaguchi, K. Mori, T. Mizugaki, K. Ebitani, K. Kaneda, J. Am. Chem. Soc.122 ( 2000) 7144-7145.

[5] K. Mori, T. Hara, T. Mizugaki, K. Ebitani, K. Kaneda, J. Am. Chem. Soc. 126 (2004) 10657-10666.

[6] H. Wang, W. Fan, Y. He, J. Wang, J.N. Kondo, T. Tatsumi, J. Catal. 299 (2013) 10-19.

[7] J. Liu, F. Wang, Z. Gu, X. Xu, Chem. Eng. J. 151 (2009) 319-323.

[8] S. Sajip, J.K. Bartley, A. Burrows, M.T. S. Schulz, A. Tuel, J.C. Volta, C.J. Kiely, G.J. Hutchings, New J. Chem., 25 (2001) 125-130.

[9] W. Zhan, Y. Guo, Y. Wang, X. Liu, Y. Guo, Y. Wang, Z. Zhang, G. Lu, J. Phys. Chem. B. 111 (2007) 12103-12110.

[10] X. Tang, J. Li, J. Hao, Catal. Commun. 11 (2010) 871-875.

[11] B. Qiao, A.Wang, M. Takahashi, Y. Zhang, J. Wang, Y. Deng, T. Zhang, J. Catal. 279 (2011) $361-365$.

[12] E.M. Slavinskaya, R.V. Gulyaev, A.V. Zadesenets, O.A. Stonkus, V.I. Zaikovskii, Yu. V. Shubin, S.V. Korenev, A.I. Boronin, Appl. Catal. B: Environ. 166-167 (2015) 91-103.

[13] Z. Miao, Y. Zhang, X. Pan, T. Wu, B. Zhang, J. Li, T. Yi, Z. Zhang, X.Yang, Catal. Sci. Technol., 5 (2015) 1314-1322.

[14] P. Zhang, H. Lu, Y. Zhou, L.Zhang, Z.Wu, S. Yang, H. Shi, Q. Zhu, Y. Chen, S. Dai, Nature Commun. 6 (2015) 8446.

[15] J. Gaálová, P. Topka, L. Kaluža, O. Šolcová, Catal. Today, 175 (2011) 231-237.

[16] L. Ma, D. Wang, J. Li, B. Bai, L. Fu, Y. Li, Appl. Catal. B: Environ. 148-149 (2014) 36-43. 
[17] W.Y. Hernandez, M.A. Centeno, F. Romero-Sarria, J.A. Odriozola, J. Phys. Chem. C, 113 (2009) 5629-5635.

[18] C. Julien, M. Massot, R. Baddour-Hadjean, S. Franger, S. Bach, J.-P. Pereira-Ramos, Solid State Ionics, 159 (2003) 345-356.

[19] A. Korotcov, H.P. Hsu, Y. S. Huang, D.S. Tsai, K.K. Tiong, Crystal Growth \& Design, 6 (2006) 2501-2506.

[20] M. Rashad, M. Rüsing, G. Berth, K. Lischka, A. Pawlis, J. Nanomater. 2013, 714853, 1-6.

[21] K.S.W. Sing, Pure Appl. Chem. 54 (1982) 2201-2218.

[22] H. Li, D. Zhang, P. Maitarad, L. Shi, R. Gao, J. Zhang, W. Cao, Chem. Commun. 48 (2012) 10645-10647.

[23] F. Li, J. Chen, Q. Zhang, Y. Wang, Green Chem. 10 (2008) 553-562.

[24] C. Wang, C. Zhang, W. Hua, Y. Guo, G. Lu, S. Gil, A.G. Fendler, RSC Adv. 6 (2016) 9957799585

[25] A.F. Carley, M.W. Roberts, A.K. Santra, J. Phys. B: Chem. 101 (1997) 9978-9983.

[26] L.F. Liotta, F. Puleo, V. La Parola, S.G. Leonardi, N. Donato, D. Aloisio, G. Neri, Electroanalysis, 27 (2015) 684-692.

[27] S. Rousseau, S. Loridant, P. Delichere, A. Boreave, J.P. Deloume, P. Vernoux, Appl. Catal. B: Environ. 88 (2009) 438-447.

[28] Y. Okawa, T. Masuda, H. Uehara, D. Matsumur, K. Tamur,Y. Nishihatad, K. Uosaki, RSC Adv., 3 (2013) 15094-15101.

[29] N. Zhang, Y. Du, M. Yin, C. Guan, J. Feng, D. Li, RSC Adv. 6 (2016) 49588-49596.

[30] L.F. Liotta, G. Di Carlo, G. Pantaleo, A.M. Venezia, G. Deganello, Appl. Catal. B. Environ. 66 (2006) 217-227.

[31] C. Zhou, F. Peng, H.Wang, H. Yu, J. Yang, X. Fu, Fuel Cells, 11 (2011) 301-308.

[32] P. Gawade, B. Bayram, A.M.C. Alexander, U.S. Ozkan. Appl. Catal. B. Environ. 128 (2012) 21-30.

[33] Y. Ji, Z. Zhao, A. Duan, G. Jiang, J. Liu, J. Phys. Chem. C 2009, 113, 7186-7199.

[34] T.M. Sankaranarayanan, A. Berenguer, C. Ochoa-Hernándeza, I. Moreno, P. Jana, J.M. Coronado, D.P. Serranoa, P. Pizarro, Catal. Today, 243 (2015) 163-172.

[35] A. G. Badalyan, P. P. Syrnikov, C. B. Azzoni, P. Galinetto, M. C. Mozzati, J. Rosa, V. A. 
Trepakov, L. Jastrabik, J. Appl. Phys. 104 (2008) 033917.

[36] G. Qi, R.T. Yang, J. Chem. Soc., Chem. Commun. 2003, 848-849.

[37] X.Tang, Y. Li, X. Huang, Y. Xu, H. Zhu, J. Wang, W. Shen, Appl.Catal. B: Environ. 62 (2006) 265-273.

[38] Z. Ding, L. Li, D. Wade, E.F. Gloyna, Ind. Eng. Chem. Res. 37 (1998) 1707-1716. 


\section{A list of caption to figures:}

Fig.1 XRD patterns of catalysts (a) Mn-Ce, (b) Ru-Mn-Ce, (c) Ru-Mn-Ce (300), (d) Ru-Mn-Ce (500) and (e) Co-Ce, (f) Ru-Co-Ce, (g) Ru-Co-Ce (300), (h) Ru-Co-Ce (500).

Fig.2 Raman spectra of catalysts (a) Ru-Mn-Ce; (b) Ru-Mn-Ce (500); (c) Ru-Co-Ce; (d) $\mathrm{Ru}-\mathrm{Co}-\mathrm{Ce}(500)$.

Fig.3 TEM images of (a) Ru-Mn-Ce, (b) Ru-Mn-Ce (500), (c) Ru-Co-Ce, (d) Ru-Co-Ce (500) catalysts and SEM images of (e) Ru-Mn-Ce, (f) Ru-Mn-Ce (500), (g) Ru-Co-Ce, (h) Ru-Co-Ce (500) catalysts

Fig.4 XPS spectra of (A) Mn 2p, (B) O 1s of catalysts (a) Ru-Mn-Ce, (b) Ru-Mn-Ce (300), (c) Ru-Mn-Ce (500) ; (C) Co 2p, (D) O 1s of catalysts (d) Ru-Co-Ce, (e) Ru-Co-Ce (300), (f) Ru-Co-Ce (500); (E) Ru 2p of (a) Ru-Mn-Ce, (b) Ru-Mn-Ce (300), (c) Ru-Mn-Ce (500), (d) Ru-Co-Ce, (e) Ru-Co-Ce (300) and (f) Ru-Co-Ce (500) catalysts.

Fig.5 $\mathrm{H}_{2}$-TPR profiles of (a) Mn-Ce, (b) Ru-Mn-Ce, (c) Ru-Mn-Ce (300), (d) Ru-Mn-Ce (500), (e) Co-Ce, (f) Ru-Co-Ce, (g) Ru-Co-Ce (300) and (h) Ru-Co-Ce (500) catalysts.

Fig.6 EPR spectra of samples at $300 \mathrm{~K}$ (a) Ru-Mn-Ce, (b) Ru-Mn-Ce (500), (c) Ru-Co-Ce and (d) Ru-Co-Ce (500) catalysts. 